\title{
Análise ergonômica do trabalho e o reconhecimento científico do conhecimento gerado
}

\author{
Carlos Antonio Pizo,*, Nilton Luiz Menegon ${ }^{\mathrm{b}}$ \\ a,*capizo@uem.br, UEM, Brasil \\ bmenegon@dep.ufscar.br, UFSCar, Brasil
}

\section{Resumo}

Este texto contextualiza na Análise Ergonômica do Trabalho (AET) as preocupações de pesquisadores da área de ergonomia sobre o reconhecimento científico dos métodos de pesquisa sobre o trabalho. Com base nessas preocupações e numa revisão sobre as características da pesquisa-ação é feita uma análise teórica da simbiose entre esse método de pesquisa e a AET, e como isto contribui para que os conhecimentos gerados na AET possam ter seu reconhecimento científico facilitado junto aos pares das áreas de conhecimento em que a ergonomia permeia.

Palavras-chave

Ergonomia da atividade. Pesquisa. Ciência.

\section{Introdução}

Iniciando com uma sucinta apresentação da análise ergonômica do trabalho, este texto parte de duas visões: a primeira busca, tendo por pano de fundo a análise ergonômica do trabalho, levantar as preocupações de pesquisadores da área de ergonomia sobre o tema "cientificidade do conhecimento na ergonomia da atividade" e a segunda sobre a metodologia da pesquisa-ação e suas características.

0 objetivo do texto é, a partir desses pontos de vistas, promover uma discussão sobre a provável indissociabilidade entre 0 método da análise ergonômica do trabalho (AET) e o método da pesquisa-ação como forma de o conhecimento gerado nos trabalhos realizados na ergonomia da atividade ter seu reconhecimento científico mais facilmente aceito pelos pares das áreas de conhecimento em que a ergonomia permeia.

Essa questão é relevante quando se observa que a pesquisa-ação é uma metodologia de pesquisa reconhecida por diversas áreas de conhecimento que tratam do trabalho e permeiam a ergonomia, e a metodologia AET está mais restrita ao núcleo da ergonomia. Essa restrição da AET solicita a "tradução" desse método para outro quando se deseja validar no núcleo de uma área de conhecimento os resultados das pesquisas realizadas. Geralmente esse outro método é a pesquisa-ação, pois a AET carrega muita semelhança em seus procedimentos e proposta, mas com uma abordagem particular: compreender o trabalho para transformá-lo.

\section{Análise ergonômica do trabalho}

A partir de 1955, após a publicação do livro de Faverge e Ombredane sobre a análise do trabalho, a atuação de diversos outros pesquisadores expoentes na área fez com que a ergonomia centrada na análise da atividade fosse desenvolvida ao longo do tempo, tendo suas bases teóricas aprofundadas, seus métodos enriquecidos e suas aplicações às transformações das condições de trabalho mais elaboradas (GÜÉRIN et al., 2001; MONTMOLLIN, 2007; LAVILLE, 2007).

Essa evolução levou a reconhecer a ergonomia situada como um dos dois principais conjuntos de ergonomias, distinguidos tanto na sua história como nos conceitos e nas práticas, mas que se complementam. 0 primeiro conjunto, majoritário no mundo e baseado no contexto americano e 
britânico, corresponde à ergonomia clássica e é qualificado como centrado no componente humano dos sistemas homem-máquina. 0 segundo, enraizado principalmente nos países francófonos, é classificado como focado na atividade humana contextualizada. Essa dicotomia entre as duas principais famílias de ergonomias assenta-se em modelos, quadros teóricos e diferentes métodos, sendo transversal em relação às ergonomias identificadas em função dos diferentes domínios de intervenção (MONTMOLLIN, 2007).

No contexto da ergonomia centrada na atividade, Güérin et al. (2001) colocam que transformar o trabalho é a finalidade primeira da ação ergonômica, e o que o ergonomista deve realizar de forma a contribuir para:

- A concepção de situações de trabalho que não alterem a saúde dos trabalhadores e nas quais estes possam exercer suas competências, ao mesmo tempo num plano individual e coletivo, e encontrar possibilidade de valorização de suas capacidades; e

- Alcançar os objetivos econômicos determinados pela empresa, em função dos investimentos realizados ou futuros.

Para os mesmos autores a busca desses dois objetivos origina a análise ergonômica do trabalho, cujo método busca resolver os problemas da inadequação do trabalho às características humanas gerados por:

- Projetos de sistemas de produção, de processos, da organização do trabalho e das tarefas que foram feitas, muitas vezes a partir de estereótipos simplificados do que seria a população de trabalhadores, que geralmente são "encaixados" na produção; e

- Situações de adaptação, transformação ou concepção de sistemas de produção em que houve predominância dos aspectos financeiros, técnicos ou organizacionais que não favoreceram a reflexão sobre o lugar incontornável do homem no sistema de produção. Essas situações minimizam a influência dos meios de trabalho cuja concepção não leva suficientemente em conta as especificidades de funcionamento do operador humano e a variabilidade de todo o sistema.

Para contextualizar o que seja trabalho, Güérin et al. (2001) caracterizam-no como unidade de três realidades: a das condições de trabalho, a do resultado do trabalho e a da atividade de trabalho. Destacam ainda o conceito do trabalho prescrito e do trabalho real, estabelecendo a distinção entre tarefa e atividade de trabalho. Esses conceitos são bem sintetizados por Falzon (2007), o qual também destaca as noções de regulação e da regulação da atividade.
Nesse processo de contextualização do trabalho, Güérin et al. (2001) colocam que a atividade de trabalho é o elemento central que organiza e estrutura os componentes da situação de trabalho, estabelecendo o que eles denominaram de função integradora da atividade de trabalho. Para essa construção existe um conjunto de pontos importantes, de fases privilegiadas que vão estruturar a construção ergonômica. Esse esquema está apresentado na Figura 1.

A interação que ocorre entre os atores desse processo conduzido pelo ergonomista gera um aumento do conhecimento ou do nível de consciência da atividade que será fator-chave na implementação das ações ergonômicas resultantes do diagnóstico feito e da transformação desejada.

Güérin et al. (2001) destacam ainda que parte do que se construiu deve permanecer e adquirir uma legitimidade que resista ao tempo. Construção esta realizada com a contribuição do ergonomista junto com os atores do processo. Isso está diretamente relacionado à maneira como os conhecimentos sobre o trabalho foram produzidos e transferidos entre os atores e da questão das condições de sua apropriação. As características do procedimento aplicado são centrais para assegurar essa transferência, e a sua durabilidade será, por sua vez, maior caso um conjunto de atores-chave tenha sido instrumentalizado.

Para concluir essa apresentação da análise ergonômica do trabalho, os mesmos autores colocam que sua compreensão é um meio que permite:

- Conhecer melhor e explicar melhor as relações entre as condições de realização da produção e a saúde dos trabalhadores;

- Propor pistas de reflexão úteis para a concepção das situações de trabalho; e

- Melhorar a organização dos sistemas sociotécnicos, a gestão dos recursos humanos e, em consequência, o desempenho da empresa em seu todo.

A seguir são apresentadas as preocupações dos pesquisadores sobre a cientificidade e a construção do conhecimento na ergonomia da atividade.

\section{Ergonomia da atividade e sua cientificidade}

Na comunidade da ergonomia da atividade, onde a Société d'Ergonomie de Langue Française - SELF é a entidade mais representativa, a discussão sobre sua epistemologia é considerada assunto ainda recente (SOCIÉTÉ D’ERGONOMIE DE LANGUE FRANÇAISE, 2005). Nesse contexto, a obra coordenada por Daniellou (2004a) é um recipiente onde diversos 


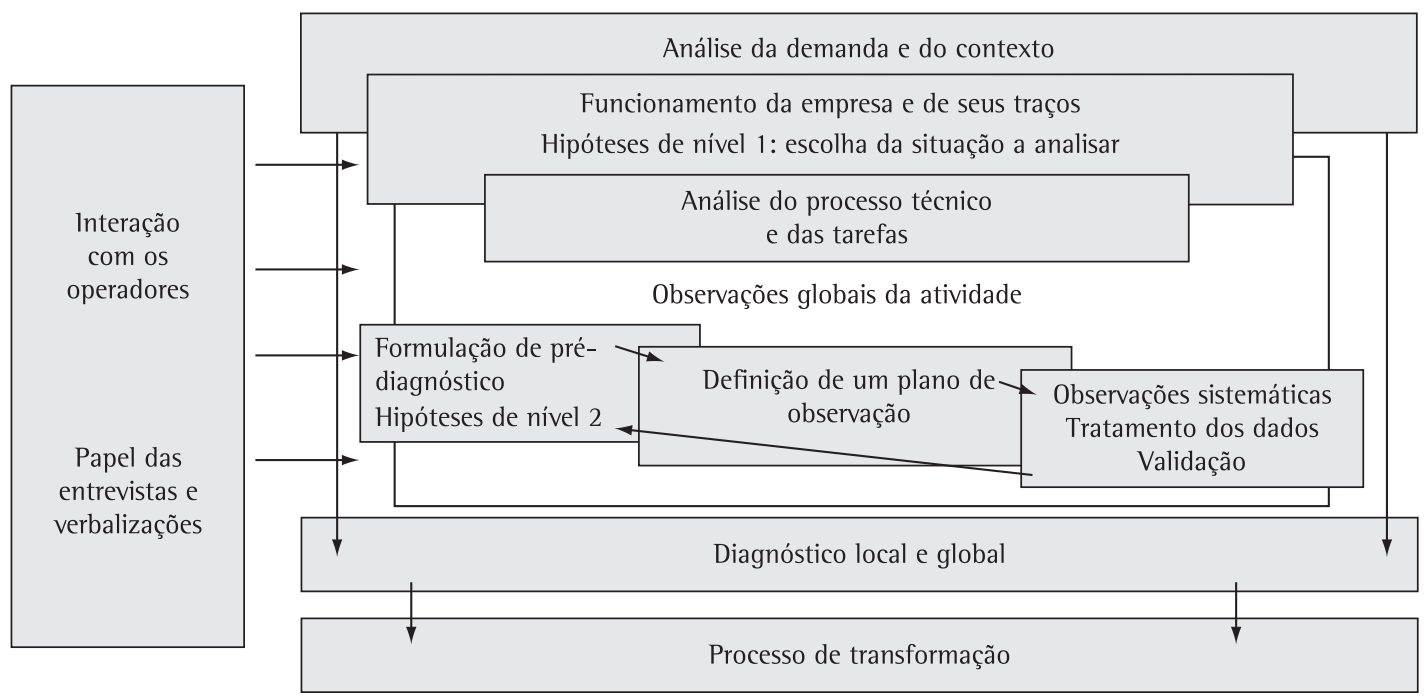

Figura 1. Esquema geral da abordagem da ação ergonômica. Fonte: adaptação de Güérin et al. (2001).

pesquisadores dessa comunidade apresentam seus pontos de vista sobre aspectos epistemológicos da ergonomia da atividade e que ainda permanece atual em seus conflitos e convergências.

É observado nessa obra que a motivação em provocar os debates sobre o tema foram as dificuldades em se obter reconhecimento científico para as pesquisas sobre o trabalho nas instituições acadêmicas. Ela, a obra, representa o esforço em se discutir de modo sistemático a contribuição da ergonomia da atividade em produzir conhecimento, em se definir seu objeto de estudo e os critérios de validação das pesquisas e intervenções práticas. Esses aspectos são destacados pela questão se a ergonomia se caracteriza como "ciência", "arte" ou "método" ser abordada em várias partes da obra.

A seguir são apresentadas algumas visões emanadas por pesquisadores sobre a questão do reconhecimento científico do conhecimento gerado na ergonomia da atividade.

\subsection{Questões epistemológicas}

Daniellou (2004b) coloca como denominador comum o fato de que a reflexão epistemológica tem por objeto as provas às quais devem se submeter as pesquisas, as teorias e os modelos que queiram merecer o adjetivo "científico". Segundo ele, todos os autores têm em comum esse cuidado de submeter seu pensamento à prova da confrontação, o que torna os conhecimentos científicos algo diferente da opinião única de seus autores. Também a elaboração das regras dessas provas não goza de unanimidade, e nesse sentido o autor faz as seguintes constatações:

- Para alguns pesquisadores, a ergonomia continuará um "projeto", uma "arte", uma "tecnologia" que utiliza conhecimentos produzidos por outras disciplinas. Se a ergonomia provoca questões de pesquisa e contribui para a produção de conhecimento, estas cairão ipso facto no acervo da disciplina científica mais bem situada para abrigá-los; e

- Para outros, a ergonomia pode produzir conhecimentos sobre a atividade de trabalho ou sobre a atividade do ergonomista, a qual the pertence exclusivamente, e que nada impede esse conhecimento de ganhar um dia a dignidade de "científico".

Para o autor é evidente que algumas das dificuldades epistemológicas com que se debate a ergonomia são comuns a todas as disciplinas que tratam do ser humano. Nesse aspecto, a pergunta-chave tornou-se dinâmica: "Que condições deveriam progressivamente preencher as pesquisas em ergonomia para que possam ser qualificadas de científicas?" Além disso, apresentada inicialmente como responsabilidade única dos pesquisadores, a questão de cientificidade das pesquisas em ergonomia passa a mobilizar outros atores: quem a pratica e os protagonistas da vida social.

Para dar base a essas constatações, o autor abre discussões sobre os seguintes aspectos:

- A consciência das bifurcações. o ergonomista é solicitado por um conjunto de teorias e modelos científicos que abrange localmente os fenômenos com os quais ele se defronta. Esses modelos não se encaixam de modo cômodo para constituir 
um corpo de conhecimentos para a ação, e em certas zonas de realidade eles se contradizem e em outras estão ausentes. Assim, a emergência de conceitos que alimentam a reflexão cotidiana do ergonomista é resultado de um conjunto de manobras, de "bifurcações". Essa condição gera uma justaposição de conceitos que dificulta a formação de um acordo do que significa produzir conhecimentos científicos em ergonomia;

- A relação entre ergonomia e os conhecimentos científicos: há um acordo latente de que a ergonomia utiliza conhecimentos oriundos da fisiologia, psicologia e outras áreas de conhecimento. Também há certa concordância de que a utilização não é uma simples aplicação desses conhecimentos, sendo que a ergonomia leva a transformá-los pelo seu caráter integrador. Por esse fato, a ergonomia é reconhecida por levar as outras disciplinas a produzir conhecimentos em zonas em que a prática as revela lacunares;

- A relação homem e o trabalho: a questão dos critérios da ergonomia está relacionada a uma discussão dos paradigmas à luz dos quais se estuda o trabalho. A ergonomia classicamente leva em conta um duplo critério - o da saúde dos trabalhadores e o da eficácia econômica - sobre o qual exige a construção de compromissos que são influenciados por diversos fatores externos. Além disso, tem-se o enigma das relações entre tarefa e atividade, o trabalho prescrito e o trabalho real, os limites da adaptação humana, os modelos do homem e suas dimensões, os modelos da sociedade e da mudança social; e

- A questão dos comportamentos à ação: a referência aos termos "comportamentos" ou "condutas" do homem no trabalho e a influência que essa perspectiva gera no desenvolvimento da ação. As questões das racionalidades (instrumental, axiológica, prática e comunicacional) que levam o ergonomista a descrever-se como ator da transformação das situações de trabalho, abrindo um espaço para discutir como ocorrem as modalidades da ação do ergonomista.

Assim, o autor apresenta uma visão geral sobre como se desenvolveram as questões que incitaram a discussão sobre a epistemologia da ergonomia da atividade.

\subsection{Questões epistemológicas levantadas pela ergonomia de projeto}

Daniellou (2004c) coloca que o estatuto dos conhecimentos em ergonomia significa saber se os conhecimentos científicos podem ser produzidos: (1) Sobre o funcionamento humano no trabalho;
(2) Sobre o trabalho; ou (3) Que sejam úteis para a sua transformação positiva.

0 autor lembra que a ergonomia foi construída nos países anglo-saxônicos dentro do paradigma da aplicação de conhecimento científicos sobre o funcionamento do homem no projeto dos meios de trabalho. Esse paradigma nas pesquisas mundiais está na origem da produção de um conjunto de conhecimentos que ainda continua útil. Mas a prática da análise ergonômica do trabalho e a confrontação com outras disciplinas (psicologia do trabalho, sociologia, psicodinâmica do trabalho, antropologia, filosofia) conduziram os pesquisadores a um conjunto de constatações que, pouco a pouco, tornou o paradigma inicial enfraquecido, entre as quais o autor cita:

- A diferença entre trabalho prescrito e trabalho real;

- 0 fato de evidenciar a atividade cognitiva e a competência dos operários;

- A complexidade dos raciocínios em inúmeras situações;

- A dimensão dos determinantes da atividade mostrada, sobretudo, pela antropotecnologia;

- A complexidade dos compromissos elaborados pelos trabalhadores e seus efeitos em termos de desempenho e de custo;

- A complexidade dos fatores de natureza coletiva que entram em jogo na elaboração de estratégias dos trabalhadores: produção de regras coletivas, dimensões éticas, ideologias coletivas de defesa; e

- A complexidade dos mecanismos de dano à saúde e o papel positivo que pode ter o trabalho na construção da saúde.

0 conjunto dessas descobertas contribuiu para reforçar o estatuto do objeto de pesquisa o trabalho propriamente dito - e o interesse pela análise da atividade como método de descoberta que permitiu não desvendar totalmente o enigma que constitui todo o trabalho, mas progredir em sua compreensão.

Diversos aperfeiçoamentos metodológicos permitiram que, progressivamente, a análise da atividade pudesse ser aplicada a quase a totalidade das atividades profissionais. Aqui o autor explica a distinção entre a análise da atividade, aquela dos comportamentos, condutas, processos cognitivos e interações realizadas por um(a) operador(a) durante as observações - da análise do trabalho -, uma abordagem mais global, na qual se insere a análise da atividade, e que se compõe da análise dos fatores econômicos, técnicos e sociais e da análise dos efeitos do funcionamento da empresa sobre a 
população de trabalhadores envolvida e da eficácia econômica.

O autor também destaca a diferença entre a análise da atividade (praticada por outros profissionais) e a análise ergonômica do trabalho. Um ponto em comum: ambas produzem conhecimentos a partir da elaboração de um modelo e da verificação de sua validade.

Uma diferença que se destaca nessa condição é que os conhecimentos produzidos a partir da análise ergonômica do trabalho estão a serviço da ação, e por isso as exigências para sua validação são mais fortes do que as consideradas na validação dos conhecimentos que são objeto central de uma busca científica. Produzido sobre dada situação de trabalho, o modelo feito pelo ergonomista deve ser operante e sua própria estrutura reflete a ambição de agir para transformar as condições de trabalho.

\subsection{Do que a ergonomia pode fazer a análise?}

\section{Hubault (2004) relata que a ergonomia tem a}

[...] missão de aprofundar a compreensão da relação entre o que o homem vive no trabalho e pelo seu trabalho, o que ele faz, com o que a empresa compreende disso, o que ela faz disto, ainda mais, o que ela espera disto, o que ela quer fazer disto [...] (HUBAULT, 2004, p. 106).

Com isso ele destaca que o ergonomista interessa-se pela relação do homem e da empresa, do homem e da técnica, do homem e seu ambiente, enfim de cada nível que se pode conceber uma interface entre esses termos. Diante do exposto se coloca uma primeira questão que é a de saber se na interface o trabalho organiza uma continuidade ou descontinuidade, finalidades e modos de ação, entre o homem e o espaço instrumental ao qual ele deve se integrar.

Como descontinuidade, Hubault (2004) coloca que a ergonomia nasceu de uma questão fundamental: a que obriga a distinguir o que se solicita ao homem (a tarefa) e o que isso, para ser realizado, solicita a ele. lsso tem origem em um conflito de lógicas, e a competência do operador é encontrar os meios de gerenciá-lo por meio de compromissos operatórios. Esse princípio de descontinuidade diz respeito a vários níveis:

- Na relação entre a atividade e o comportamento: no trabalho real que se realiza, os compromissos que o operador faz para agir não se veem e o comportamento comunica a parte manifesta do trabalho (visualmente e verbalmente);
- Em relação ao desempenho: podem-se distinguir dois tipos de saídas do sistema de produção os desempenhos econômicos e os desempenhos humanos. Os primeiros avaliáveis/avaliados em termos de eficácia na ordem econômica (rendimento, produtividade, qualidade, confiabilidade,...) e os outros em termos de eficácia na ordem humana (competência adquirida/degradada, saúde melhorada/deteriorada,...); e

- Na relação entre tarefa e atividade: onde existem duas posições opostas. Uma que postula que diferença entre o prescrito e o real é uma diferença a ser reconhecida, uma descontinuidade de princípio entre o modelo e a realidade em geral e entre a tarefa e a atividade no particular. A outra é o que se demanda e o que isso demanda, na qual a ergonomia identifica uma diferença a reduzir.

0 autor discorre que essas abordagens estão sempre em jogo, e que isso implica em saber que tipo de integração, funcional ou política, realiza a interface e o lugar que nela ocupa o trabalho (fator integrador/integrável ou de integração). Aqui ele apresenta como os diversos estados da ergonomia se enquadram dentro dos paradigmas de continuidade e descontinuidade. Nesse ponto ele abre que a ergonomia trabalha em três níveis, cada qual com suas questões e seus desafios: (1) nível das condições de trabalho (questão-adaptação; desafio-segurança/saúde); (2) nível dos sistemas técnicos (questão-eficiência; desafio-confiabilidade); e o (3) nível dos sistemas de produção (questão-eficácia; desafio-qualidade).

Diante desse complexo de relações, o autor coloca que uma das missões essenciais da ergonomia é a de

[...] formalizar a relação homem-ambiente de modo a levar em conta esta contradição: o homem é um sistema autônomo que não é determinado pela oferta informacional de seu meio, mas que não pode se construir sem ela[...] (HUBAULT, 2004, p. 116).

Assim é aberta a questão "o trabalho real é real?" Os fatos observáveis de que a ergonomia dispõe dizem respeito ao desempenho, ao comportamento, à tarefa, que ela confronta entre si e aos conhecimentos adquiridos previamente sobre o funcionamento humano, que faz emergir a figura da atividade. A partir da objetivação de fatos brutos organizados em sistemas de dados a ergonomia - uma ciência empírica - constrói, com o conceito de atividade, não observável, o meio de se compreender, de se levar em conta o que faz realmente o operador, a própria atividade.

Para embasar a questão da prática, o autor compara o processo de construção do conhecimento 
na área da psicanálise e apresenta três pontos que balizam suas propostas sobre a ergonomia:

- A prática participa de uma dimensão metodológica fundamental dos conhecimentos em ergonomia. Onde conhecer manipulando define um método de análise; conhecer para manipular define uma prática de intervenção; manipular para conhecer define uma metodologia de pesquisa. Em todos os casos visa-se o conhecimento e a manipulação de um processo e não de um estado;

- Polarizações particulares que favorecem um modo diversificado de desenvolvimento da ergonomia nutrem relações diferentes com a ciência; e

- 0 peculiar da ergonomia está no seu ponto de vista que a distingue de todas as outras áreas sobre o estudo do trabalho.

\subsection{Ergonomia, filosofia e exterritorialidade}

Schwartz (2004) destaca na ergonomia a questão da exterritorialidade dos conceitos, questionando se ao ser epistemólogo e utilizar conceitos já é, de certa maneira, julgar, decidir e engajar-se, pois qualquer uso de conceitos é uma escolha, uma reivindicação de herança, uma decisão de existência ou inexistência.

Ao utilizar conceitos, estes podem ser diferentes devido ao que o autor denominou de possíveis bifurcações na escolha de itinerários conceituais. Segundo ele, a questão "erro humano ou falha de representação" exprime com clareza esse ponto de bifurcação conceitual. Um efeito dessa bifurcação conceitual é a manifestação de escolhas mais ou menos exclusivas que implicam em itinerários de investigação previamente estabelecidos, o que caracterizaria uma parcialidade na abordagem realizada.

$\mathrm{Na}$ elaboração de sua argumentação, Schwartz (2004) faz uso de exemplos da área de ciências humanas com o intuito de mostrar que as áreas de conhecimento possuem lugares escondidos, lógicas internas que não aparecem, filiações e rupturas históricas nos sistemas conceituais. Além de remeter eventualmente a conjuntos complexos de valores e de escolhas e a uma prática que poderia ser uma boa definição de postura epistemológica. É nesse contexto que ele estabelece uma relação triangular entre valores, saberes e atividade com base nas seguintes proposições:

- Nenhuma atividade industriosa se desenvolve e se manifesta sem um espaço simultâneo de valores;

- Esse mundo de valores se comunica em todos os pontos consigo mesmo; e

- Os valores imanentes à atividade são sempre "retratados" por ela.
A partir de ensaio literário nesse contexto, o autor elabora a proposta de produzir conhecimentos compatíveis com o "policentrismo" observado nos conceitos levantados pela construção de lugares em que a relação triangular entre valores, atividades e saberes torna-se objeto de uma experiência epistemológica explícita. Neste processo é elaborada a proposta de um dispositivo (espaços de construção de saberes integrados) de três polos (Figura 2). Esse dispositivo, proposto por Schwartz (2004) e adaptado por Vieira, Barros e Lima (2007), tem a seguinte configuração:

- Polo dos saberes acadêmicos. objetos de esforço permanente de estabelecimento de uma ordem teórica, de explicitação metódica e crítica, de retrabalho contínuo. É aquele dos saberes conceituais das áreas de conhecimento permeadas pela ergonomia;

- Polo dos saberes imanentes às atividades e retrabalhados por essas atividades. são "cadinhos" da organização dos saberes, estruturando em uma base histórica seus desdobramentos sobre seus apelos aos saberes formalmente organizados. É aquele dos saberes investidos no exercício do trabalho e na experiência; e

- Polo filosófico: com vistas aos saberes organizados e com relação às forças de apelo, de memória e dos saberes investidos. Esse polo teria a função de antecipar, com as devidas reservas, as maneiras de tratar seu semelhante e as situações da vida social. É aquele que significa uma postura ética e epistemológica, presente nos projetos em comum que acordam entre si os dois outros polos.

Esse dispositivo torna-se a sede de um movimento duplo, no seu centro, onde misturam-se e operam culturas contraditórias, patrimônios tendencialmente definidos pelos três polos, e mantém-se coeso por causa de seu movimento interno em espiral e remetendo os atores de cada polo ao exercício de suas próprias responsabilidades profissionais.

Os atores "ativos" são remetidos às urgências da vida social e seu movimento de retorno é, em parte, para avaliar a pertinência do trabalho realizado no interior do dispositivo, com uma eventual vocação para o retorno, redesenhando os recursos do saber e desenvolvendo novas forças de apelo. Quantos aos atores "profissionais do conceito", tanto no polo filosófico como no dos saberes acadêmicos organizados, eles são enviados às suas disciplinas de origem a fim de que participem, agora devidamente equipados, do debate científico que lhes é próprio.

Esse processo no núcleo do dispositivo é denominado pelo autor de "socratismo ambivalente", pois o sentido da troca de conhecimento (mestre/ 


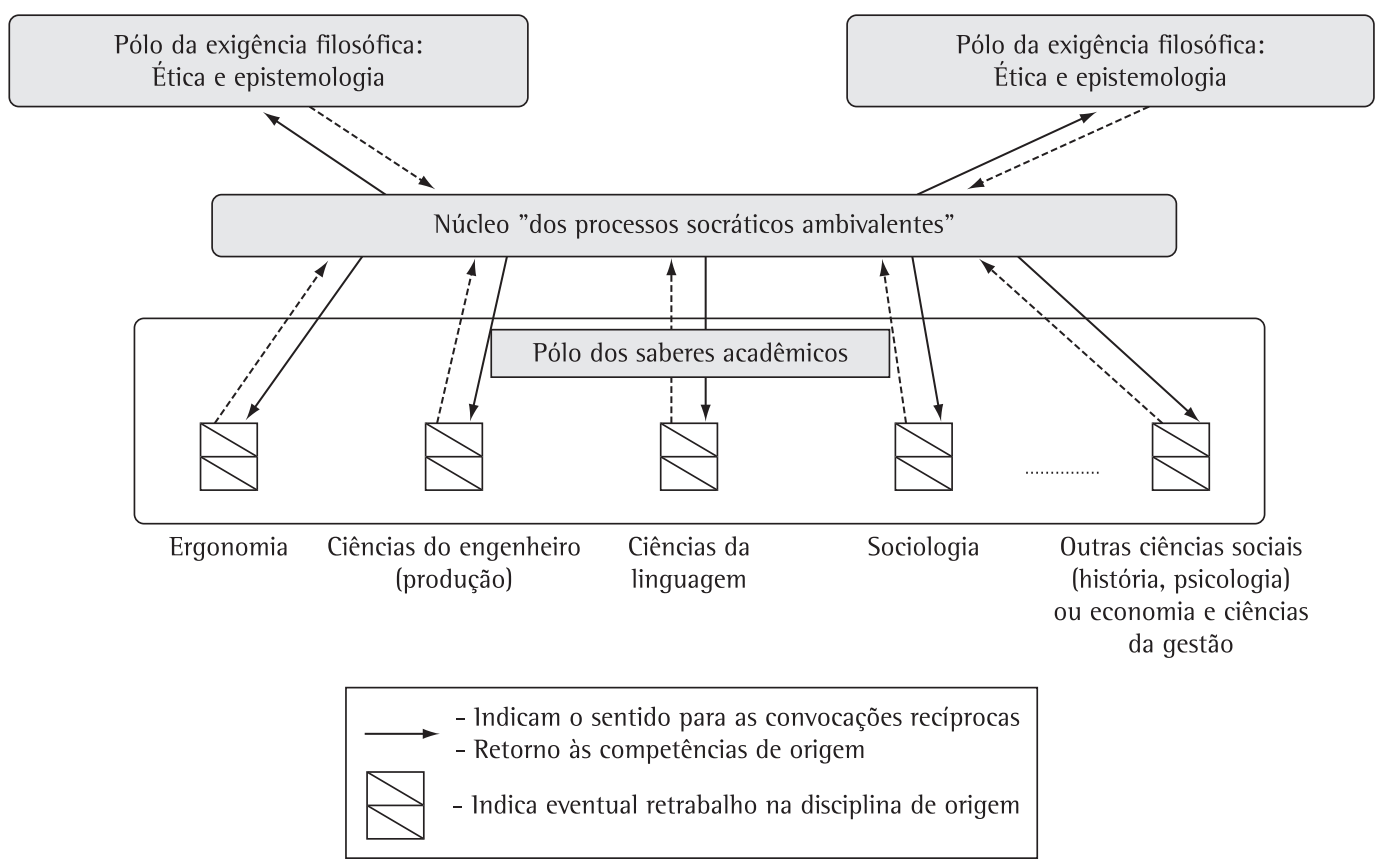

Figura 2. Dispositivo dinâmico de três polos de produção de saber. Fonte: adaptação de Schwartz (2004).

discípulo) é alternado frequentemente entre os atores, sendo difícil identificá-lo no decorrer do processo.

A epistemologia associada a esse gênero de dispositivo requer que se confronte rotineiramente as normas que lhe são próprias (socratismo ambivalente e a disponibilidade a outras estruturas conceituais) e as normas vigentes na comunidade científica de referência, pois elas são a garantia de uma reapropriação crítica e de uma vigilância específica quanto ao patrimônio acumulado no seio da disciplina.

Por fim o autor, questionando se a ergonomia é ciência, coloca que quanto mais ela se torna ciência, menos pertinente ela se torna como interlocutora imediata de sujeitos históricos. Quanto mais a competência ergonômica se aproxima das pressões da transformação in situ, mais ela deve posicionar-se para a aprendizagem no triângulo atividades/ valores/saberes e menos se justifica a eliminação dos protagonistas ou forças de apelo-memória, compreendendo-se o ponto de vista científico.

Portanto, a capacidade de mover-se no triângulo, instaurando grupos cooperativos e fazendo emergir questionamentos pertinentes, é apoiada por uma ampla cultura adquirida sobre a atividade, especialmente o que se pode capitalizar no polo mais regulamentado cientificamente, no sentido tradicional da ergonomia.

\subsection{A importância da AET para o estágio de maturidade da ergonomia como ciência}

Bouyer (2007), utilizando-se do conceito de quatro limiares que distinguem o grau de maturidade de um discurso científico (positividade, epistemologização, cientificidade e formalização), coloca que a ergonomia está situada entre o limiar da epistemologização e o da cientificidade. Para ele a caracterização da ergonomia como ciência encontra-se confusa, porém mais conscienciosa da necessidade da interdisciplinaridade na construção da ergonomia científica e não reducionista.

Se a opção é considerar a ergonomia ciência, o autor observa que os modelos explicativos devem acompanhar a evolução das disciplinas que se unem para consolidá-los. Nesse contexto interdisciplinar

[...] não há limite nos conhecimentos das disciplinas, que podem ser recrutados para a interpretação de uma atividade de trabalho [...] (DANIELLOU, 2004c, p. 187).

No processo de maturidade em direção à cientificidade, Bouyer (2007) considera que o passo mais largo nessa direção foi a metodologia da análise ergonômica do trabalho (AET). Ela trouxe uma nova mentalidade sobre o que consiste estudar uma situação de trabalho, colocando a atividade de trabalho como espaço privilegiado. 0 mesmo autor observa que essa situação demandou 
[...] incluir todo um arcabouço científico de outras disciplinas (psicologia, antropologia, fisiologia,...) que, integradas, deveriam dar conta do objeto posto para análise da ergonomia: o trabalho, a atividade [...] (BOUYER, 2007, p. 4).

Tecendo a discussão em torno dos fundamentos sobre cientificidade e métodos, conclui-se que com o instrumental da AET é:

[...] possível construir verdadeiros modelos que, conforme postulada pela filosofia da ciência em diferentes abordagens, podem ser considerados modelos científicos por permitir, ao observador, explicar o fenômeno mediante o emprego desta ferramenta ou modelo por ele construído[...] (BOUYER, 2007, p. 5).

\subsection{Sintese}

Como destacado por Daniellou (2004a), a própria origem multidisciplinar do início da ergonomia colabora para reforçar as questões levantadas pelos autores, e observa-se que não há um consenso quanto ao status da ergonomia (ciência, arte ou método), sendo que cada visão segue uma tendência baseada nas origens metodológicas que a embasaram. Uma percepção abstraída da leitura dos textos permite que se tente estabelecer uma linha de foram considerados:

- A ergonomia da atividade se desenvolve da ação. Assim, todo trabalho em ergonomia deve ser baseado em um trabalho de campo que irá constituir o ambiente necessário para o completo desenvolvimento do conhecimento em ergonomia;

- A compreensão da existência do dispositivo de três polos proposto por Schwartz (2004) para que se identifiquem os atores em cada polo e seus linguajares, e com isso conhecer os ambientes onde o conhecimento será gerado e validado;

- Compreender a descontinuidade organizada pelo trabalho e a complexidade de relações estabelecidas observadas por Hubault (2004), de modo a determinar procedimentos criteriosos para o registro dos conhecimentos gerados e das ferramentas utilizadas na realização do trabalho-pesquisa; e

- Realizar o trabalho de campo através da análise ergonômica do trabalho como ferramenta principal para a geração dos dados brutos (fatos virtuais ou reais) que serão fontes do desenvolvimento do conhecimento em ergonomia.

Essa conduta básica oferece uma estruturação do trabalho de pesquisa em ergonomia da atividade que permite estabelecer um vocabulário mais amplo e formalizado de forma que atenda a todos os atores que irão validar o que foi desenvolvido. Observa-se nas leituras que os pesquisadores trazem de suas áreas de origem os termos e vocabulários (linguajares) utilizados em seus trabalhos, e isso normalmente gera áreas de atrito pelo fato de não entrarem em consenso sobre a amplitude de seus significados. Para amenizar essa situação existem publicações que buscam definir e estabelecer limites para vários termos dentro do contexto da ergonomia (MONTMOLLIN, 2007; KARWOWSKI, 2006; STRAMLER, 1993).

0 uso da AET é fundamental para essa construção do conhecimento por permitir, conforme observado por Bouyer (2007), que as verificações por outros membros da comunidade científica sejam realizadas, visto que as fases para tal são fornecidas nas etapas da própria AET e o modelo surge desse conjunto resultante da validação pelos próprios atores.

\section{Metodologia da pesquisa-ação}

Neste tópico é apresentada uma visão sucinta da metodologia de pesquisa-ação, uma metodologia cuja definição não é trivial. Para Tripp (2005), a definição da pesquisa-ação é difícil por duas razões interligadas: primeiro é um processo tão natural que se apresenta, sob muitos aspectos, diferente; e, segundo, ela se desenvolveu de maneira distinta para diferentes aplicações. Por esse motivo o autor coloca que deve-se reconhecer que a pesquisa-ação é um dos inúmeros tipos de investigação-ação, que é um termo genérico para qualquer processo que siga um ciclo no qual se aprimora a prática pela oscilação sistemática entre agir no campo da prática e investigar a respeito dela.

Na breve revisão da origem histórica do método da pesquisa-ação, apesar de muitos atribuírem sua criação a K. Lewin por este ter cunhado o termo em 1946, o mesmo autor elenca diversos trabalhos que poderiam ser reconhecidos como base do método. Para ele, a identificação de saber quando e onde o método teve origem é difícil porque as pessoas sempre investigaram a própria prática com a finalidade de melhorá-la.

Franco (2005) realça que desde o aparecimento do termo e após diferentes incorporações teóricas ao conceito e à prática da pesquisa-ação, muitas interpretações têm sido realizadas em nome dela. Isso gerou um mosaico de abordagens metodológicas, que muitas vezes se operacionalizam na práxis investigativa, sem a necessária explicação de seus fundamentos teóricos, gerando inconsistências entre teoria e método e comprometimentos à validade científica dos estudos.

A mesma autora destaca a existência no método da pesquisa-ação do ciclo em espiral de três fases proposto por Lewin, que permite readequações e alterações de rumo do processo. Tripp (2005) identifica que a maioria dos processos de melhoria segue esse mesmo ciclo e apresenta 
alguns desenvolvimentos do processo básico de investigação-ação (Quadro 1).

Para restringir o termo pesquisa-ação à forma de investigação-ação mais específica à pesquisa acadêmica, Tripp (2005) prefere que ela seja denominada como

[...] uma forma de investigação-ação que utiliza técnicas de pesquisa consagradas para informar a ação que se decide tomar para melhorar a prática [...] (TRIPP, 2005, p. 447),

e na qual essas técnicas devem atender aos critérios comuns a outros tipos de pesquisa acadêmica (como, por exemplo, enfrentar a revisão pelos pares quanto a procedimentos, significância, originalidade, validade, etc.).

Com viés mais sociológico, Thiollent (2005) classifica a pesquisa-ação como uma linha de pesquisa associada a diversas formas de ação coletiva orientada em função da resolução de problemas ou de objetivos de transformação. Ele a distingue da metodologia da pesquisa participante, pois na pesquisa-ação, além da participação, ela supõe uma forma de ação planejada de caráter social, educacional, técnico ou outro, que nem sempre se encontra em propostas de pesquisa participante.

Thiollent (2005) ainda limita a pertinência do alcance da pesquisa-ação à faixa intermediária entre o que é geralmente designado como nível microssocial (indivíduos, pequenos grupos) e o que é considerado como nível macrossocial (sociedade, movimentos e entidades de âmbito nacional ou internacional). Essa faixa intermediária de observação corresponde a uma grande diversidade de atividades de grupos e indivíduos no seio ou à margem de instituições ou coletividades. Nesse aspecto é destacado que, na abordagem da interação social adotada em sua caracterização, os aspectos sociopolíticos são mais frequentemente privilegiados que os da realidade psicológica e existencial. Do ponto de vista sociológico, a proposta de pesquisa-ação dá ênfase à análise das diferentes formas de ação. 0 que é também observado por Franco (2005) sob um ponto de vista educacional.

Embora a abordagem de Thiollent (2005) priorize o lado empírico, ele não deixa de colocar as questões relativas aos quadros de referência teórica sem os quais a pesquisa empírica - pesquisa-ação ou não - não faria sentido e sobre o qual está relacionada ao papel da teoria na pesquisa. Ele destaca a contribuição específica dos pesquisadores nos discursos que acompanham o desenrolar da pesquisa e em conduzir uma deliberação acerca dos argumentos a serem levados em conta para estabelecer as conclusões. Essa ponte entre o
Quadro 1. Processos de investigação-ação.

\begin{tabular}{|c|c|}
\hline Nomenclatura & Autores \\
\hline Pesquisa-ação & Lewin (1946) \\
\hline Aprendizagem-ação & Revons (1971) \\
\hline Prática reflexiva & Schön (1983) \\
\hline Projeto-ação & Argyris (1985) \\
\hline Aprendizagem experimental & Kolb (1984) \\
\hline Ciclo PDCA & Deming (1986) \\
\hline $\begin{array}{l}\text { PLA - Participatory Learning and Action } \\
\text { PAR - Participatory Action Research } \\
\text { PAD - Participatory Action Development } \\
\text { PALM - Participatory Action } \\
\text { Learning Methods } \\
\text { PRA - Participatory Rural Appraisal } \\
\end{array}$ & Chambers (1983) \\
\hline Prática deliberativa & McCutcheon (1988) \\
\hline Pesquisa práxis & Whyte $(1964 ; 1991)$ \\
\hline Investigação apreciativa & $\begin{array}{c}\text { Cooperrider e } \\
\text { Shrevasteva (1987) }\end{array}$ \\
\hline Prática diagnóstica & $\begin{array}{l}\text { Genérica em medicina, } \\
\text { ensino corretivo, etc }\end{array}$ \\
\hline Avaliação-ação & Rothman (1999) \\
\hline Aprendizagem transformacional & Marquardt (1999) \\
\hline
\end{tabular}

Fonte: Tripp, 2005.

empirismo e a teoria no método da pesquisa-ação é bem abordada por Argyris, Putnam e Smith (1985).

Com base no contexto apresentado, o autor considera que a pesquisa-ação é uma estratégia metodológica da pesquisa social na qual:

- Há uma ampla e explícita interação entre pesquisadores e pessoas implicadas na situação investigada;

- Dessa interação resulta a ordem de prioridade dos problemas que serão pesquisados e das soluções a serem encaminhadas sob forma de ação concreta;

- 0 objetivo da investigação não é constituído pelas pessoas e sim pela situação social e pelos problemas de diferentes naturezas encontrados nessa situação;

- 0 objetivo da pesquisa-ação consiste em resolver ou, pelo menos, esclarecer os problemas da situação observada;

- Há, durante o processo, um acompanhamento das decisões, das ações de toda a atividade intencional dos atores da situação; e

- A pesquisa não se limita a uma forma de ação (risco de ativismo): pretende-se aumentar o conhecimento dos pesquisadores e o conhecimento ou o "nível de consciência" das pessoas e grupos considerados.

Para Franco (2005), no questionamento "de que pesquisa se fala” quando se refere à pesquisa-ação, as respostas devem ser norteadas pelas seguintes dimensões:

- Dimensão ontológica: referente à natureza do objeto a ser conhecido e cuja questão principal é o que se pretende conhecer quando se utiliza a pesquisa-ação a partir de pressupostos iniciais; 
- Dimensão epistemológica: referente à relação sujeito-conhecimento e cuja questão principal é como se estabelecem as relações entre sujeito e conhecimento; e

- Dimensão metodológica: referente a processos de conhecimento utilizados pelo pesquisador e que passa fundamentalmente à exigência de procedimentos articuladores da ontologia com a epistemologia da pesquisa-ação.

Outra questão-chave na pesquisa-ação colocada por Thiollent (2005) é a elucidação dos objetivos que ele coloca como relacionamento entre dois tipos:

- Objetivo prático: que seria contribuir para o melhor equacionamento possível do problema considerado como central na pesquisa, com levantamento de soluções e proposta de ações correspondentes às soluções para auxiliar o agente (ou ator) na sua atividade transformadora da situação; e

- Objetivo de conhecimento: que seria obter informações de difícil acesso por meio de outros procedimentos e aumentar o conhecimento de determinadas situações.

A relação entre esses dois tipos é variável, sendo que o autor considera que com maior conhecimento a ação é mais bem encaminhada. Assim, a ênfase no alcance do trabalho pode ser dada a um de três aspectos: resolução de problemas, tomada de consciência ou produção de conhecimento. Bem conduzido, o trabalho pode alcançá-los simultaneamente.

Thiollent (2005) ainda destaca que é necessário ter cuidados para que a pesquisa-ação resulte em conhecimentos associados ao ideal científico. Com ela é necessário produzir conhecimento, adquirir experiência, contribuir para a discussão ou fazer avançar o debate acerca das questões abordadas. Nesse processo, parte das informações geradas é divulgada para a população envolvida na pesquisa, sob forma e meios apropriados. A outra parte, cotejada com resultados de pesquisa anteriores, é estruturada em conhecimentos e divulgada pelos canais próprios da área do pesquisador. A estrutura cognitiva oferece ao pesquisador melhores condições de compreensão, decifração, interpretação, análise e síntese do "material" qualitativo gerado na situação investigada. "Material" este essencialmente feito de linguagem, sob formas de simples verbalizações, imprecações, discursos ou argumentações mais ou menos elaboradas.

0 mesmo autor coloca que a significação do que ocorre na situação de comunicação estabelecida pela investigação passa pela compreensão e a análise da linguagem em situação, pois é necessário um mínimo de conhecimento nesse setor para evitar ingenuidades. Parte dessa atividade é um processo argumentativo que se encontra:
- Na colocação dos problemas a serem estudados conjuntamente por pesquisadores e participantes;

- Nas “explicações” ou "soluções” apresentadas pelos pesquisadores e que são submetidas à discussão entre os participantes;

- Nas "deliberações" relativas à escolha dos meios de ação a serem implementados; e

- Nas "avaliações" dos resultados da pesquisa e da correspondente ação desencadeada.

Com a pesquisa-ação pretende-se alcançar realizações, ações efetivas, transformações ou mudanças no campo social. A questão da ação transformadora deve ser colocada desde o início da pesquisa em termos realistas e estabelecido o papel do pesquisador. Nesse aspecto várias situações podem ser distinguidas:

- Quando os participantes têm uma ideia clara dos objetivos e da ação necessária, em que o pesquisador essencialmente assessora as decisões correspondentes ao que for factível nas melhores condições e extraem da prática diversos ensinamentos;

- Quando se trata de uma ação tipo técnica, ela é definida em função dos meios técnicos e econômicos necessários, em função do saber próprio dos usuários e do contexto social; e

- Quando se trata de uma ação de caráter cultural, educacional ou político, os pesquisadores e participantes devem estar em condição de fazer uma avaliação realista dos objetivos e dos efeitos.

Diferenciando o método da pesquisa-ação, Thiollent (2005) coloca que na pesquisa-ação há um reconhecimento do papel ativo dos observadores na situação investigada e dos membros representativos dessa situação. Nesse processo, a noção de objetividade estática é substituída pela noção de relatividade observacional, segundo a qual a realidade não é fixa e o observador e seus instrumentos desempenham um papel ativo na captação da informação e nas decorrentes representações. Essa interação entre o observador e o observado não é unilateral entre o pesquisador e os investigados; ela é de duas vias, onde todos desempenham uma função interrogativa, fazendo perguntas e procurando elucidar os assuntos coletivamente investigados. Isso remete aos desníveis de abstração no modo de comunicação dos pesquisadores e dos participantes devido às diferenças de linguagem.

No plano da ação, segundo Thiollent (2005), o desafio maior é o de juntar as exigências da tomada de consciência (ou da conscientização, a um nível mais profundo) com as exigências científico-técnicas. As transformações intencionalmente definidas não se traduzem apenas ao nível da consciência individual ou coletiva, há também a aprendizagem de saber fazer e aquisição de novas habilidades. 
0 mesmo autor destaca também que o saber informal dos participantes não é desprezado e sim posto em relação com o saber formal dos especialistas no intuito do enriquecimento mútuo. Quanto ao aspecto de geração de conhecimento, a pesquisa-ação fortalece a produção e a divulgação de conhecimentos que, apesar de nãos serem valorizados no plano cultural-simbólico, são de grande utilidade na resolução de problemas do mundo real. 0 autor conclui que a pesquisa-ação é uma orientação destinada ao estudo e à intervenção em situações reais.

Nesse processo de geração de conhecimento, Tripp (2005) considera útil empregar cinco modalidades ao pensar sobre a natureza de um projeto de pesquisa-ação:

- Pesquisa-ação técnica: abordagem pontual na qual toma-se uma prática existente de algum outro lugar e a implementa em sua própria esfera de prática para realizar uma melhora;

- Pesquisa-ação prática: abordagem onde se escolhe ou projeta as mudanças dentro do próprio espaço de melhoria;

- Pesquisa-ação política: refere-se à mudança cultural institucional e/ou de suas limitações;

- Pesquisa-ação socialmente crítica: modalidade da anterior, cujo resultado é uma mudança no modo de pensar a respeito do valor último e da política das limitações; e

- Pesquisa-ação emancipatória: Variação da pesquisa-ação política que tem como meta explícita mudar o stato quo de um grupo social como um todo.

0 autor fecha sua análise colocando que uma pesquisa-ação é tão eficaz, cientificamente ou não, quanto as pessoas que a realizam.

\section{Considerações finais}

Como apontado por Montmollin (2007), a ergonomia não é só análise da atividade, bem como a análise da atividade pode ser utilizada em outros domínios que não o do trabalho. Contudo, a partir das discussões apresentadas, é possível levantar os seguintes aspectos-chave sobre o método da ergonomia da atividade:

- Ela se desenvolve da ação;

- Os atores são todos os que participam do processo, inclusive o pesquisador/ergonomista;

- A interação entre os atores gera um aumento do conhecimento ou do nível de consciência da atividade, que será fator chave para a transformação da situação do trabalho;
- É um método cíclico que se realimenta do conhecimento ou aumento da consciência gerado; e

- 0 trabalho deve ser realizado tendo a análise ergonômica do trabalho como ferramenta principal para a geração dos dados brutos (fatos virtuais ou reais).

Como comentado por Daniellou (2004a) e detalhado por Leplat e Montmollin (2007) para as áreas de biologia humana, medicina do trabalho, ciências cognitivas, psicologia do trabalho, sociologia do trabalho e organização do trabalho, entre outras, a ergonomia possui um caráter integrador de conhecimentos oriundos de várias áreas. lsso faz com que o conhecimento gerado no âmbito da ergonomia seja levado para essas diversas áreas.

Esse processo de retornar ao "meio" da área de conhecimento feito pelos pesquisadores faz com que o pesquisador tenha de "traduzir" o método de pesquisa reconhecido pelos pares do "meio" da ergonomia para um método reconhecido pelos pares da sua área de conhecimento de origem. Em muitas áreas de conhecimento em que a ergonomia permeia o método da pesquisa-ação, é um método de pesquisa reconhecido e utilizado em diversos propósitos de estudo, apesar das discussões sobre o controle que se deve ter para manter seu caráter científico.

Por outro lado, as preocupações sobre a cientificidade da ergonomia da atividade e os aspectos destacados sobre o método da análise ergonômica do trabalho permitem observar que a AET tem forte semelhança com as características e preocupações relacionadas à pesquisa-ação. 0 esquema geral da abordagem da ação ergonômica no desenvolvimento da análise ergonômica do trabalho proposto por Güérin et al. (2001), a interação entre os atores e a participação ativa do pesquisador levantadas por Daniellou (2004a, b, c), os aspectos instrumentais e de comunicação destacados por Hubault (2004) e Schwartz (2004), respectivamente, fazem com que a proximidade entre o método da análise ergonômica do trabalho e o da pesquisa-ação os torne indissociáveis para que o conhecimento gerado seja reconhecido mais amplamente nas diversas áreas de conhecimento.

Não que seja o único método de pesquisa a ser utilizado, pois isso depende do objetivo da pesquisa em ergonomia, mas com certeza será o método para qualificar melhor a análise ergonômica do trabalho nos espaços da área de conhecimento integrada à ergonomia que não a permeiam.

0 pesquisador, conseguindo caracterizar essa simbiose entre pesquisa-ação e análise ergonômica do trabalho, colocando a última como uma situação 
particular da primeira, terá mais facilidade em movimentar-se entre os espaços de conhecimento dentro de sua área de atuação. Isso ocorre pela redução da necessidade de "tradução" do método AET nessas movimentações, principalmente considerando as variações e denominações do método pesquisa-ação observado por Tripp (2005) e Franco (2005).

Essa expectativa decorre, como posto por Daniellou (2004b) e Tripp (2005), pelo fato de que uma pesquisa para ser reconhecida tem que ser validada pela comunidade em que ela é apresentada e que sua aceitação depende em parte do método utilizado e de sua condução. Por isso é importante que a condução da pesquisa e a representação do conhecimento sejam aceitas pela comunidade na qual se quer validá-la.

Como colocado pelos mesmos autores, a aceitação não é estática, unânime e se altera com o tempo, conforme a área do conhecimento vai evoluindo. Assim, os trabalhos desenvolvidos devem ser sempre submetidos à comunidade para obter conhecimentos de como está evoluindo o seu pensar sobre o tema, o método e também para modificar esse caminho.

Uma continuidade desse trabalho será 0 levantamento das produções científicas que tenham lançado mão da análise ergonômica do trabalho para: identificar o método de pesquisa adotado; a comunidade a qual pertencem os pesquisadores e qual trabalho foi apresentado. Com isso será possível averiguar a realidade dessa indissociabilidade e a chance de uma possível classificação da análise ergonômica do trabalho como um tipo de pesquisa-ação com propósitos ergonômicos.

\section{Referências}

ARGYRIS, C.; PUTNAM, R.; SMITH, D. M. Action Science: Concepts, methods, and skills for research and intervention. San Francisco: Jossey-Bass, 1985.

BOUYER, G. C. A ciência ergonômica entre a epistemologização e a cientificidade. In: ENCONTRO NACIONAL DE ENGENHARIA DE
PRODUÇÃo, 27., 2007, Foz do lguaçu. Anais... Foz do lguaçu: PUC-PR, 2007.

DANIELLOU, F. Apresentação à edição brasileira. In: DANIELLOU, F. (Coord.). A ergonomia em busca de seus princípios: debates epistemológicos. São Paulo: Edgard Blucher, 2004a. p. 8-10.

DANIELLOU, F. Introdução - questões epistemológicas acerca da ergonomia. In: DANIELLOU, F. (Coord.). A ergonomia em busca de seus princípios. debates epistemológicos. São Paulo: Edgard Blucher, 2004b. p. 1-18.

DANIELLOU, F. Questões epistemológicas levantadas pela ergonomia de projeto. In: DANIELLOU, F. (Coord.). A ergonomia em busca de seus princípios. debates epistemológicos. São Paulo: Edgard Blucher, 2004c. p. 181-198.

FALZON, P. Natureza, objetivos e conhecimentos da ergonomia: elementos de uma análise cognitiva da prática. In: FALZON, P. (Ed.). Ergonomia. São Paulo: Edgard Blucher, 2007. p. 3-19.

FRANCO, M. A. S. Pedagogia da Pesquisa-ação. Educação e Pesquisa, v. 31, n. 3, p. 483-502, 2005.

GÜÉRIN, F. et al. Compreender o trabalho para transformá-lo: a prática da ergonomia. São Paulo: Edgard Blucher, 2001.

HUBAULT, F. Do que a ergonomia pode fazer análise? In: DANIELLOU, F. (Coord.). A ergonomia em busca de seus princípios: debates epistemológicos. São Paulo: Edgard Blucher, 2004. p. 105-140.

KARWOWSKI, W. Encyclopedia of ergonomics and human factors. London: Taylor \& Francis, 2006.

LAVILLE, A. Referências para uma história da ergonomia francófona. In: FALZON, P. (Ed.). Ergonomia. São Paulo: Edgard Blucher, 2007. p. 21-32.

LEPLAT, J.; MONTMOLLIN, M. As relações de vizinhança da ergonomia com outras disciplinas. In: FALZON, P. (Ed.). Ergonomia. São Paulo: Edgard Blucher, 2007. p. 33-44.

MONTMOLLIN, M. Vocabulaire de l'Ergonomie. Tolouse, France: Octarès Editions, 2007.

SCHWARTZ,Y. Ergonomia, filosofia e exteritorialidade. In:DANIELLOU, F. (Coord.). A ergonomia em busca de seus princípios. debates epistemológicos. São Paulo: Edgard Blucher, 2004. p. 141-179.

SOCIÉTÉ D'ERGONOMIE DE LANGUE FRANÇAISE - SELF. Ergonomie de l'activité et francophonie: héritages, réalités, perspectives. 2005. Disponivel em: <http://www.ergonomie-self.org/diffusion/ contributions.pdf>. Acesso em: 01 jun. 2008.

STRAMLER, J. H. The dictionary for human factors/ergonomics. Boca Raton, Florida: CRC, 1993.

THIOLLENT, M. Metodologia da pesquisa-ação. 14 ed. São Paulo: Cortez, 2005.

TRIPP, D. Pesquisa-ação: uma introdução metodológica. Educação e Pesquisa, São Paulo, v. 31, n. 3, p. 443-466, 2005.

VIEIRA, C. E. C.; BARROS, V. A.; LIMA, F. P. A. Uma abordagem da psicologia do trabalho, na presença do trabalho. Psicologia em Revista, v. 13, n. 1, p. 155-168, 2007.

\title{
Ergonomic work analysis and the scientific recognition of knowledge generated
}

\begin{abstract}
This paper contextualizes in Ergonomic Work Analysis (EWA) the concerns of researchers in the field of ergonomics regarding the scientific recognition of research methods in their work. Based on these concerns and a review of the characteristic activity of research, a theoretical analysis is undertaken of the symbiosis between this method of research and EWA, and of how this contribution to knowledge generated in EWA may have facilitated its scientific recognition among peers of the areas of knowledge that ergonomics permeates.
\end{abstract}

Keywords

Activity ergonomics. Research. Science. 